\title{
USO DE REGULADORES DE CRESCIMENTO NA GERMINAÇÃO DE SEMENTES DE MARACUJÁ AMARELO SUBMETIDAS AO ESTRESSE HÍDRICO
}

\author{
Paula Aparecida Muniz de Lima ${ }^{1}$ \\ Khétrin Silva Maciel ${ }^{2}$ \\ Rodrigo Sobreira Alexandre ${ }^{3}$ \\ José Carlos Lopes ${ }^{4}$
}

Resumo: Objetivou-se com o presente trabalho estudar a germinação de sementes de maracujá amarelo tratadas com reguladores de crescimento e submetidas ao estresse hídrico. A germinação das sementes foi feita em rolos de papel germitest, colocados em câmaras de germinação tipo $B O D$, à temperatura de 20 $30^{\circ} \mathrm{C}$. Foram utilizados os reguladores de crescimento: poliamina, ácido giberélico, 6-benzilamina 6-purina e ácido 4-(3-indolil) butírico nas soluções de manitol com potencial osmótico 0,0 e -0,4 MPa. Foram avaliados: germinação, índice de velocidade de germinação, comprimento da parte aérea e raiz e massa seca de plântulas. O delineamento experimental foi inteiramente ao acaso, com esquema fatorial $5 \times 2$ (cinco reguladores de crescimento $x$ dois agentes osmóticos). Os reguladores de crescimento atenuam os efeitos do estresse hídrico. As sementes de maracujá amarelo tratadas com reguladores de crescimento não foram eficientes para germinação e IVG.

Palavras-chave: Potenciais osmóticos; Qualidade fisiológica; Vigor.

\footnotetext{
1 Agronomia/Universidade Federal do Espírito Santo, Brasil. E-mail: aluap-lima@hotmail.com.

2 Agronomia/Universidade Federal do Espírito Santo, Brasil. E-mail: khetrinmaciel@gmail.com.

3 Agronomia/Universidade Federal do Espírito Santo, Brasil. E-mail: rodrigosobreiraalexandre@gmail.com.

${ }^{4}$ Agronomia/Universidade Federal do Espírito Santo, Brasil. E-mail: jcufes@bol.com.br.
} 